\title{
DOS COMENTARIOS A LENGUAJE, CONOCIMIENTO Y REALIDAD EN LA TEORÍA DE LAS IDEAS DE PLATÓN DE FABIÁN MIÉ
}

\section{Manuel Berrón}

Es reconfortante enterarse de que en nuestro país se siguen editando obras de filosofía, y más reconfortante aún cuando estas obras son de filosofía antigua, especialmente de Platón. Tal es el caso de la obra de reciente publicación Lenguaje, conocimiento y realidad en la teoria de las ideas de Platón elaborada por Fabián Mié (UNC-CONICET). Esta obra propone una relectura de los diálogos medios de Platón bajo un conjunto estimulante de hipótesis que invitan a la meditación sobre la totalidad del corpus platónico. Si bien está estructurada en base a la discusión de estas hipótesis se la puede considerar también como una obra de acceso y de estudio en detalle de algunos de los principales diálogos platónicos, como son, v.g., Fedón, Parménides, Crátilo, Teeteto y República entre otros, y de las principales tesis filosóficas allí presentadas ${ }^{1}$. La obra, presentada por M. D. Boeri y sometida a una evaluación anónima, consta de 408 páginas de las cuales unas 29 constituyen una importante reseña bibliográfica de las fuentes de Platón y de los más importantes estudios críticos de los últimos 50 años, así como también de las distintas herramientas de trabajo propias de la filosofía antigua, i.e., diccionarios, índices y repertorios. Tal vez la principal dificultad para el lector no especializado sean algunas referencias a términos griegos, cuando no oraciones enteras, que no se encuentran traducidos o transliterados y que, desde luego, dificultan la interpretación para el lego en esa lengua. Quizás también hubiera sido conveniente algún tipo de índice de los pasajes analizados o de las referencias a los diálogos realizadas.

Las hipótesis que estructuran y ordenan el texto combaten una

${ }^{1}$ Creo oportuno excusarme de comentar toda la obra y temas abarcados no sólo porque el lugar y espacio no lo permiten sino también por las múltiples referencias a todo el corpus platónico y a los numerosísimos estudios críticos. No estoy en condiciones de dar cuenta de todas estas referencias y estudios. 
imagen tradicional y difundida de la metafísica de los "dos mundos" platónica. Mié entiende -y lo justifica con una amplia referencia a buena parte de las obras platónicas así como a numerosos estudios críticos- que Platón se encuentra lejos de esta caracterización clásica del platonismo acerca no sólo de su metafísica sino también de ciertas implicancias en su lógica y su epistemología. En este sentido entonces se esfuerza por rechazar, por ejemplo, que las ideas sean entidades básicas accesibles a un conocimiento de carácter intuitivo; rechaza además que Platón sostenga una teoría del lenguaje meramente referencialista y una teoría del conocimiento que descanse en el modelo del contacto sensible directo. Acorde además con esta imagen tradicional del platonismo se suele entender que los diálogos tardíos constituyen una etapa autocrítica de Platón que supone el abandono de las ideas, implicando una crisis de la metafísica de los "dos mundos" y de la separación. Al contrario, Mié defiende una posición "compatibilista". Según ésta, habría que comprender el conjunto de los diálogos tardíos como una crítica del período medio que no implica en sí misma una destrucción de la hipótesis de las ideas; antes bien, implicaría un perfeccionamiento de la hipótesis misma o, que es decir lo mismo, la solución a distintos problemas implicados por ella. No habría entonces una discrepancia entre la teoría de las ideas del período medio y la dialéctica tardía, y en este sentido se negaría la interpretación según la cual habría diferencias entre el Platón "maduro" y el "de vejez".

Para el autor, la interpretación evolutiva termina siendo muchas veces una solución simple a dificultades hermenéuticas complejas, v.g., el hecho de que el joven Sócrates del Parménides se vea desarmado por el Extranjero de Elea implicaría no sólo una crítica a las ideas sino el alejamiento de Platón de las mismas, por el contrario, para Mié, el Parménides constituye básicamente una crítica al monismo eléata y no un alejamiento de la teoría de las ideas. Tres son los motivos por los cuales supone que la teoría de las ideas nunca perdió vigencia (cfr.: $\$ 1.1$, p. 24-27): el primero lo elabora a partir del encendido ataque que Aristóteles realiza a la teoría: ¿por qué motivo se esforzaría Aristóteles por atacar algo ya perimido o, planteado en otros términos, por qué criticaría algo que supuestamente ya no es defendido por su principal representante? El segundo reside en el hecho de que las ideas tienen plena vigencia en el Timeo, obra indudablemente tardía en la cual las ideas se presentan con toda su vitalidad. En esta obra, todas las críticas del Parménides y el Sofista no han hecho mella, ¿qué otro motivo 
puede justificar este hecho sino que las ideas estén aún vigentes? El tercer y último motivo allí esbozado es la nula recepción en Aristóteles del Parménides. Este hecho impediría elaborar un supuesto itinerario intelectual de Platón según el cual éste habría abandonado las ideas.

Contra esta posición, sin embargo, pueden argumentarse algunos tópicos en los cuales se observa con claridad un cambio de opinión en el pensamiento de Platón. Si bien los argumentos planteados con anterioridad son atendibles, cabe aclarar que se limitan a uno de los aspectos del pensamiento platónico, tal vez mejor decir, a uno de los temas tratados por Platón, i.e., el concerniente a la teoría de las ideas. Por otra parte, para poner un ejemplo y tal como M. Boeri también observa en la presentación (p. 13), la psicología o teoría del alma elaborada en Fedón no es asimilable sin más a la de República IV. En este punto no se puede considerar a la interpretación hermeneútico-evolutiva meramente como una salida fácil ante cuestiones peliagudas. Voy a argumentar en favor de esta "evolución", o al menos, "cambio de opinión" en el pensamiento de Platón respecto de la cuestión del alma para volver luego sobre el valor de la interpretación hermenéuticoevolutiva.

En el Fedón ${ }^{2}$, en su diálogo con Cebes, a partir de 78a ss., Sócrates arguye a favor de la inmortalidad del alma. Su estrategia pasa por mostrar que el alma es uno de los cuerpos simples. Establece primero que lo que es compuesto puede descomponerse, y por lo tanto perecer, mientras que lo que es simple es eterno o incorruptible. En segundo lugar, pone de manifiesto que las realidades en sí, las ideas, no admiten cambio o mutación sino que se encuentran siempre en idéntico estado; por otra parte, se encuentra la multiplicidad de cosas que nos rodean, hombres, caballos, mantos y demás cosas, éstas se encuentran todas sujetas a la corrupción, nunca las encontramos en el mismo estado sino que siempre difieren respecto de sí mismas. Luego distingue: estas últimas realidades son visibles mientras que a las ideas las aprehendemos por medio de la inteligencia y la reflexión y por lo tanto son invisibles. Se identifica entonces, por una parte,

\footnotetext{
${ }^{2}$ Me voy a limitar al Fedón ya que es uno de los diálogos estudiados por Mié. Pienso que también podrían haberse considerado algunos pasajes del Protágoras. Sin embargo, evalué que es mejor dejarlo de lado ya que este último es considerado como un diálogo socrático, lo que por su parte introduciría otro objeto de polémica más.
} 
lo inmutable o eterno con lo invisible y por otra, a lo perecedero o mortal con lo visible. Luego se afirma que el cuerpo pertenece al género visible, y por ende pertenece a lo perecedero. $\mathrm{El}$ alma por su parte es más afín, por medio del pensamiento, a las ideas, que no son visibles. Como consecuencia de todo esto se deduce que el alma es simple, no visible, afín a las ideas, y por lo tanto inmortal, que era lo que se quería demostrar. Al margen de esta reflexión, pero de interés para la contraposición con Rep. IV, en 66a ss., se describe la "liberación" que opera la filosofía en el alma. La liberación se da respecto de los deseos que se originan en el cuerpo. El alma puede llegar a conocer siempre y cuando se libere del cuerpo y todo lo que él trae aparejado. En síntesis, lo que nos interesa resaltar para nuestra argumentación es que en este pasaje se ve claramente que el alma o bien es pura o bien busca purificarse de los deseos y de todo lo que la dimensión corporal implica. El conflicto entre deseo y razón debe buscarse entre el alma y el cuerpo; en ningún caso podemos hablar de un conflicto en el alma. Por último me refiero al pasaje de $94 \mathrm{~b}$, allí claramente se observa que la sed y el hambre -deseos- se originan en el cuerpo y que el alma se opone a ellos y los domina, o no; esta referencia es interesante ya que Platón trata el mismo caso en República IV.

En Rep. IV, 436a ss. se introduce la tan discutida tesis sobre la tripartición del alma. La postura platónica en este pasaje argumenta en contra del monismo y a favor de la tripartición, las partes reconocidas son la racional, la fogosa y la apetitiva. Sólo quiero remarcar la distinción entre la parte racional y la apetitiva o, simplemente, la referida a los placeres. Hay una afirmación de peso en 436b-c, lo suficientemente rigurosa como para ser contrapuesta a la del Fedón. La misma se puede presentar así: es imposible que un mismo sujeto sufra al mismo tiempo cosas opuestas en la misma parte y con respecto de lo mismo; si hubiera efectos contrarios, se originarían en partes contrarias. Se puede apreciar que esto ya se diferencia de lo planteado en Fedón de modo que origina un contexto para la discusión del tema absolutamente distinto de aquél. Un poco más adelante, en $437 \mathrm{~d}$ ss. se discute el ejemplo al que se hacía referencia en Fedón: el del hambre y la sed. Luego de una detallada discusión sobre la naturaleza del objeto del apetito, se llega al pasaje en el que se establece la distinción entre las partes del alma. En 439b-e se desarrolla entonces el argumento para establecer las partes: hay personas que deseando comer o beber, es decir, teniendo sed o hambre, sin embargo, no comen o no beben. En estas personas hay un 
impulso que los manda a beber o a comer y otro que los retiene, el primero impulsa como a una bestia, mientras que el segundo actúa mesurando y tratando de instaurar el autocontrol. De acuerdo al principio establecido unas líneas antes (436b-c) estos impulsos contrarios no pueden más que originarse en partes contrarias del alma. Quedan así establecidas la parte apetitiva del alma y la parte racional. Luego se propone el ejemplo de Leoncio, donde éste siente deseo de ver ciertos cadáveres y su razón le dice "con enojo" todo lo repugnante del espectáculo que verá. Platón introduce así una nueva distinción y con ella la tercera parte del alma, la parte fogosa o colérica, que a veces está del lado de los deseos y a veces del lado de la razón. Contraponiendo finalmente estas líneas a Fedón podemos ver con claridad que ha habido un cambio de opinión, se ha trasladado el conflicto entre cuerpo y alma a las partes del alma. El conflicto ahora es dentro del alma y entre sus partes, de este modo se ha puesto en entredicho el monismo psicológico a partir de la tripartición ${ }^{3}$.

Los argumentos elaboradamente planteados por Mié a lo largo del libro para mostrar su tesis de la no contradicción entre el Platón maduro y el de vejez son suficientes como para sostener su posición, pero de todos modos no por eso debe dejarse descartada sin más y considerada como una solución facilista a la interpretación evolutiva; esto lo probaría el ejemplo anterior. Teniendo en cuenta lo planteado en párrafos anteriores y los 40 años de producción platónica no puede descartarse fácilmente esta hipótesis. Finalmente, respecto de este punto, concuerdo con Mié en un cuidadoso y equilibrado eclecticismo metodológico a la hora de estudiar los diferentes diálogos platónicos.

En el primer capítulo de la obra se trabaja especialmente el Fedón. Acorde con su tesis central comentada líneas arriba, en este capítulo se va a tratar de establecer (v. \ 2.1) que la "trascendencia" de las ideas, que supone la separación, no conduce directamente a la postulación de la metafísica de los "dos mundos". De hecho, aceptando la dualidad de mundos se crea el

${ }^{3}$ En el marco de su análisis del Fedón, Mié elabora una noción de "respectos" -que comento unas líneas más abajo- según los cuales se puede analizar en una misma entidad diferentes aspectos. Según plantea (cfr. p. 32) se podría contemplar desde esta lógica la tripartición del alma, que de hecho, no dañaría la unidad. De todos modos, yo no considero que este análisis logre equipararse a lo afirmado en República IV en los pasajes presentados. 
insalvable problema de la comunicación entre ellos. A partir de la caracterización clásica del "platonismo" acerca del mundo sensible, espacio heraclíteo del devenir y el cambio permanentes, que se contrapone al orden ideal, parmenídeo y estático, se estableció que las cosas sensibles son compuestas y múltiples, mientras que las ideas son simples y unitarias. Mié se pregunta si esta caracterización supone necesariamente la no combinación entre ideas o si, por el contrario, a pesar de esta caracterización, es posible un concepto de idea que no excluya la combinación entre lo uno y lo múltiple. Argumenta a partir del pasaje del Fedón 102b-d, en donde se discute que en el mismo individuo se den la grandeza y la pequeñez. Allí está ya presente una cierta combinación de y entre las ideas. La discusión dialéctica elaborada en este pasaje, donde se está discutiendo la inmortalidad del alma, examina distintas relaciones entre ideas, combinaciones y exclusiones entre ellas. Según Mié, las ideas funcionan como "respectos" (p. 33) que hacen posible el conocimiento de los particulares. En un sujeto X se dan la grandeza y la pequeñez, en él se dan simultáneamente un conjunto de estos "respectos", de ideas, que no obstante ello permanecen inmutables y uniformes, y de hecho, sin esta característica no podrían ser condición del conocimiento. Grandeza y pequeñez siguen siendo inmutables, sin embargo, como "respectos", las podemos encontrar en un mismo sujeto. Las ideas son la condición necesaria para el conocimiento, por ese motivo son descritas como "lo que es algo" o "lo que es idéntico", deben permanecer idénticas a sí para poder ser el fundamento del conocimiento. Sin embargo, esto no implica necesariamente la afirmación ontológica de la separación o dicho en otros términos, la susbtancialización de las ideas. Tampoco implica la concepción eléata de las ideas, antes bien, las ideas son entre sí combinables, desde luego que no todas las combinaciones son posibles, pero lo que sí queda claro es que hay comunicación entre las ideas.

El último capítulo, el $\mathrm{V}$, el más largo y complejo de la obra, de unas 150 páginas, se centra en el estudio del Teeteto. Allí se trabajan buena parte de los temas desarrollados en el diálogo: las tres definiciones de lo que es conocimiento, la tesis protagórea del bomo mensura, el "sueño" de Sócrates, y, especialmente, la última parte del diálogo. Mié entiende que el Teeteto es un diálogo de transición de los diálogos medios a la dialéctica tardía cuyo objetivo central está en presentar las aporías que suponen una ontología y epistemología que toman como base un modelo del conocimiento directo de 
correlatos objetuales (p. 231). En este sentido, Platón estaría discutiendo un modelo epistemológico que hace imposible su propia teoría de las ideas ( $p$. 238). Además, considera sugestivo -y realmente lo es- que las ideas no sean una de las hipótesis analizadas allí como solución al problema del conocimiento. Esto potencia, según él, la hipótesis precedente de que las respuestas al problema del conocimiento que se presentan no son una solución viable, lo que en cierto sentido estaría sugiriendo que las ideas pueden serlo.

Es imposible aquí detallar todos los aspectos discutidos en el capítulo por lo que sólo voy a limitarme a comentar algunos detalles de su análisis de la primera definición del conocimiento para pasar a la parte final del texto $(y$ del diálogo). Desde su perspectiva, la primera tesis discutida en el diálogo aquella que equipara el conocimiento con la percepción apelando al movilismo absoluto atribuido a Heráclito y al relativismo de la percepción ${ }^{4}$ es de vital importancia para discutir y esclarecer una cierta consideración recurrente del platonismo. Ésta tiene que ver con la frecuente atribución hecha a Platón de considerar lo sensible en los términos de un movilismo absoluto que habría heredado de -una particular interpretación- Heráclito. Aceptar esta visión tradicional implicaría aceptar también, junto con el movilismo, el relativismo perceptual protagóreo; así las cosas, se llegaría a una consideración de lo sensible que haría imposible el conocimiento. Según Mié, Platón estaría rechazando el "rancio empirismo de la doctrina protagórea” (p. 269) que reduce la percepción a meros datos 'atómicos' desvinculados entre sí; esta teoría estaría negando la función cognitiva representacional propia de la mente humana. La capacidad de 'representar' que tiene la mente humana supondría como condición para tal acto las formas, i.e., las ideas. No puede entonces interpretarse la percepción como un mero intercambio de cosas o un choque entre entes móviles ya que una consideración tal, deducida de Heráclito y Protágoras, se vería refutada por numerosos ejemplos de la percepción, como son lo que argumenta Sócrates contra Teeteto en el diálogo. En la percepción misma se estaría dando ya una función epistémica representacional que es condición para la elaboración del conocimiento. Los objetos sensibles, según esta interpretación, son, simultáneamente, puro dato sensible, por un lado, y objeto sensible estructurado por la propia percepción humana, por otro.

${ }^{4}$ Lectura que Platón hace del dictum de Protágoras. 
Esto último implicaría en lo sensible una cierta estructura proposicional dada por las ideas. Esta lectura, ampliamente desarrollada y sumamente estimulante, merece una atención mucho más minuciosa que la que se puede hacer acá para poder determinar su alcance, validez, y correcta fundamentación en los textos presentados. De todos modos, como corolario de estas reflexiones, queda implícita la abolición de la imagen tradicional de lo sensible que se suele atribuir a Platón y la apertura a una nueva interpretación.

Me voy a referir ahora a un aspecto de la lectura final del Teeteto para terminar de esbozar la propuesta de Mié y para hacer luego algunas contraposiciones críticas a partir de un pasaje clásico o, al menos, sugerir algunos interrogantes. Después de un análisis pormenorizado de la llamada doctrina del sueño de Sócrates ${ }^{5}$ (cfr. Tht. $201 \mathrm{~d} 8$ - 202c6) el autor realiza un análisis sobre la forma en que Platón considera a la gramática. El conocimiento de las letras supone el conocimiento sobre cómo $\multimap$ la manera en qué- se combinan estas letras. Las letras aisladas no tienen sentido, su naturaleza depende de sus combinaciones posibles. Platón establece una correspondencia entre las letras y las ideas de modo que, siempre al decir de Mié, 'las ideas son 'partes' elementales de la realidad y están estructuradas por reglas de combinación", (p. 370). De este modo, conocer las formas, ideas, implica el conocimiento de los fenómenos. $Y$ de esto se sigue también que los fenómenos no son elementos simples sino que se encuentran ya de por sí constituidos, "combinados", por ideas. El que conoce, conoce las reglas de combinación de las formas. La tesis protagórea-heraclítea se hace insostenible como forma de entender lo sensible, y de este modo no sólo quedan dejados de lado estos autores sino que también tiembla la interpretación tradicional de lo sensible en Platón. Otra conclusión importante para la tesis de Mié es que las formas implican siempre un cierto lógos, de modo que no son conocidas por medio de una intuición intransferible, también el punto de vista de la interpretación del platonismo, sino que son el fruto de un análisis racional, del método dialéctico, de la discusión. El dato sensible, qua parte de un todo, sólo puede ser "leído" como formando parte de ese todo a partir de las ideas, que constituyen la

${ }^{5}$ Es llamativa la detallada reconstrucción conceptual hecha de la doctrina del sueño en p. 338-342, lo que implica un esfuerzo considerable para poder seguirla, por su tamaño y por su complejidad. 
única forma de entenderlo. El método hipotético que es utilizado por ejemplo en República sería "expresión clara del funcionamiento compositivo de las formas" (p. 371). Las aporías del Teeteto, encontradas en la doctrina del sueño, deben ser entendidas como una negación de Platón respecto de la posibilidad de fundar el conocimiento proposicional en una base no proposicional (p. 378). Esto implica entonces la negación de intuiciones de elementos simples como principios del conocimiento y la afirmación de que no hay conocimiento si no es explicativo. Explicar es, por su parte, dar cuenta de la estructura de las cosas, y esto sólo puede ser realizado apelando a las ideas.

Quisiera cerrar este comentario más que con un análisis sobre una cuestión particular, con interrogantes sugeridos por la lectura del texto. Considero interesante, además, la confrontación de las tesis de Mié con un texto clásico a la hora de la enseñanza de Platón como es el del símil de la línea (Rep. VI, 509e-511e). Mié lo analiza en p. 86-91, § 7.3 del capítulo II de su obra. Desde luego que el punto de vista del autor va a negar la distinción entre "dos mundos", pero no quisiera ahora ahondar en este aspecto de la cuestión porque ya lo hemos planteado antes. Quisiera detenerme mejor en uno de los temas más urticantes del pasaje: el referido al bien y a su captación. Según el autor, el principio anhipotético, el bien, sólo puede ser alcanzado por el dialéctico mediante la intelección (noûs). Por otra parte, las hipótesis dependen de este principio, y éstas son del orden de las ciencias, como por ejemplo las matemáticas. Así se distingue entre la epistéme dialéctica y las ciencias particulares como formas de conocer lo mismo: las entidades inteligibles. La razón discursiva (diánoia) queda reservada a las ciencias mientras que la intuición (noesis) al acceso a los principios. La noesis implica entonces una aprehensión y comprensión del eidos: "el correlato propio del nous es la propiedad formal de todo eidos qua eidos. la idea del bien, la forma de la idealidad, la unidad de los componentes formales que representan unidad y multiplicidad" (p. 89). Además, en la línea se representa el proceso cognitivo que, a partir de lo sensible, concluye en los principios, pero no por medio de cuatro "facultades" distintas y dos niveles objetuales diversos -que se encontrarían representados por los segmentos de la línea-, al contrario, habría que pensar en niveles de comprensión de acuerdo a los cuales la razón va conociendo. Cabe preguntarse entonces si esta caracterización del bien como principio anhipotético, que sólo puede ser conocido de una manera particular -mediante el nô̂s- no invalida, o se 
encuentra en contradicción, con las ideas como fueron caracterizadas más arriba (en el análisis del Fedón y en el párrafo anterior respecto del lógos en el Teeteto). Mié salva esta dificultad observando, y quejándose (p. 88), porque la diferencia planteada entre filosofía y ciencia por Platón a partir de la línea dividida no está adecuadamente justificada, y por lo tanto tampoco está claro de qué se trata el bien y su conocimiento particular. Igualmente, esta presunta insuficiencia da lugar a la tesis de los "intuicionistas". Cabe acotar además que la polémica entre los especialistas sobre este punto está lejos de haberse cerrado, al contrario, hay toda una línea de interpretación que avala una posición "intuicionista" respecto del conocimiento del bien que jugaría en contra de la posición de Mié6. Otro interrogante que se desprende del anterior es sobre la presunta jerarquía entre el bien y las demás ideas: si Mié tiene razón y su análisis de las ideas incluye al bien, ¿cómo puede explicarse la jerarquía? Creo que este tipo de interrogantes ponen ciertos límites a la interpretación de Mié (aunque desde luego no la invalidan). De todos modos, las respuestas a ellos no son unívocas, hecho constatable en la crítica especializada, pero precisamente este hecho los hace aún más interesantes.

Haciendo una valoración general de la obra, reitero que considero importante no sólo una reflexión general sobre la herencia del "platonismo" tal como lo caracteriza Mié, aún cuando eso no implique acordar con él en todos los puntos, sino también una reflexión sobre aquello que se transmite bajo el título "Platón". Creo que hay muchos lugares comunes del "platonismo" que se suelen filtrar en nuestra concepción de lo que Platón es y que la discusión erudita, como Mié lo ejemplifica, nos llama correctamente la atención sobre esto. Por último, quiero repetir lo filosóficamente estimulante que es la obra sobre numerosísimos tópicos del platonismo pero también, quizás lo más destacable, sobre la filosofía en su sentido más amplio.

${ }^{6}$ Mié da cuenta de esta línea; pueden consultarse las notas 47, 48, 49 y 53. 